\title{
Chromatic Characteristics of Copper Glaze as a Function of Copper Oxide Addition and Sintering Atmosphere
}

\author{
Hyunggoo No, Soomin Kim, Ungsoo Kim ${ }^{\dagger}$, and Wooseok Cho \\ Ceramicware Center, Korea Institute of Ceramic Engineering and Technology, Icheon 17303, Korea
}

(Received October 4, 2016; Revised November 30, 2016; Accepted December 30, 2016)

\begin{abstract}
Examined in this study were the effects of copper oxide (II) addition and sintering conditions on the chromatic characteristics of copper glaze. Oxidatively sintered samples exhibited the negative increase of $\mathrm{CIEa}^{*}$ and the positive increase of $\mathrm{CIEb}^{*}$ with the increase of $\mathrm{CuO}$ concentration, leading to Green and Green-Yellow coloration. On the other hand, $\mathrm{CIEa}^{*}$ and $\mathrm{CIEb}^{*}$ of reductively sintered samples were positively increased in direct proportion. The green color of oxidatively sintered samples was originated from the $\mathrm{Cu}^{2+}$ ions formed by the dissolution of $\mathrm{CuO}$. The reductively sintered samples resulted in dull tone red color with low chroma. Such behavior seems to be influenced by the interplay of metal $\mathrm{Cu}$ aggregation, metal $\mathrm{Cu}$ globule, and $\mathrm{Cu}_{2} \mathrm{O}$ formed in the glaze layer through the redox interaction of $\mathrm{CuO}$ during the sintering process.
\end{abstract}

Key words : Raw material, Glaze, Copper Oxide, Color, Mechanism

\section{Introduction}

D ongwha or Jinsa is a red pigment inherent to our country with copper as the color forming composition. In 2005, National Museum of Korea has reviewed the problem of terms in the mixed use of Dongwha or Jinsa (copper-red pigment) and adopted "Dongwha" for use. Koryo Dongwha porcelain developed around the $12^{\text {th }}$ century was the first case of color formation in red from the pigment of copper composition at high temperatures. Considering that such technology in China was started after Won Dynasty in the $14^{\text {th }}$ century and became perfected during the early Ming Dynasty in the $15^{\text {th }}$ century, the excellence in ceramic technology of our country can be supposed. ${ }^{1)}$

In the previous studies explaining color formation mechanisms for copper red glaze and copper ruby glass produced by using copper oxides, metallic $\mathrm{Cu}$ or copper oxide (I) particles formed in the reduction process were described as the cause for color formation. ${ }^{2-7)}$ Such division in the opinions on the cause for color formation appears to be due to the differences in composition of the specimens analyzed and in heat treatment processes. While domestic investigators also considered metallic $\mathrm{Cu}$ as the main cause for color formation, $\mathrm{BaO}$ was used as one of the flux compositions in the case of Dongwha glaze used for analysis unlike the composition for Dongwha glaze in Koryo and Chosun era analyzed by Hwang Hyeonseong in 2008 in. $^{8-10)}$ Composition of the glaze can act as an element affecting not only glossiness, illuminance and texture but also color formation. ${ }^{11)}$

\footnotetext{
${ }^{\dagger}$ Corresponding author: Ungsoo Kim

E-mail : ukim@kicet.re.kr

Tel : +82-31-645-1422 Fax : +82-31-645-1485
}

In the present study, the basic glaze was prepared based on composition of Dongwha porcelain in Chosun era, and the specimens of Dongwha glaze were prepared by variation in added amounts of copper oxide (II) and heat treatment atmospheres. To clarify the color formation mechanisms for Dongwha glaze, correlations with the colors were investigated by conducting spectroscopic, crystal phase, and microstructure. From here, attempts have been made to develop the technologies utilized for porcelain and inorganic pigment areas by defining the factors affecting color formation of our inherent Dongwha pigment, and by developing compositions and process technologies to realize stable colors.

\section{Experimental Procedure}

For glaze preparation, the basic glaze composition was determined by referring to the chemical composition analysis results of the excavated remains of Dongwha glaze. By unity molecular formula UMF method, the ratio between alkali and alkaline earth oxide was set to be $0.2: 0.8$, and the ratio between alumina and silica to be $0.46: 3.50$. For the alkaline earth oxide, $\mathrm{CaO}$ and $\mathrm{MgO}$ were used in a similar way to that for the Chosun Dongwha porcelain. The basic glaze was prepared by mixing Buyeo feldspar, sodium carbonate, limestone, magnesium carbonate, silica, kaolin, and alumina weighed according to the composition ratio with distilled water to the ratio of $65 \mathrm{wt} . \%$ for solid content. Copper oxide (II) of $0,0.5,1,3$, and $5 \mathrm{wt} . \%$, respectively, was added to this mixture, and mixed by using ball mill for $24 \mathrm{~h}$.

As the porcelain used for experiments, white porcelain capable of minimizing the effects due to impurities such as $\mathrm{Fe}_{2} \mathrm{O}_{3}$ and $\mathrm{TiO}_{2}$ was used. The bisque white porcelain specimens of $50 \times 50 \mathrm{~mm}$ in size were sintered after plop glazing 
with 5 types of the glaze prepared above. Heat treatment atmosphere was controlled by using the mixed gas of air and liquefied petroleum gas, LPG. Air supply amount was fixed at $5 \mathrm{~L} / \mathrm{min}$, and the atmosphere was controlled by varying $\mathrm{LPG}$ supply to $0,0.3,0.5$, and $0.7 \mathrm{~L} / \mathrm{min}$. For heat treatment, temperatures were raised at $3^{\circ} \mathrm{C} / \mathrm{min}$ to $900^{\circ} \mathrm{C}$ where the reducing atmosphere was formed by supply of LPG, followed by being held at $1250^{\circ} \mathrm{C}$ for $1 \mathrm{~h}$ and subsequent natural cooling.

By using the spectrophotometer (CM-700D, Konica Minolta, Japan), the glaze surface was subjected to colorimetry for 5 times and average values of CIELAB and Munsell Color values were calculated by employing SpectraMagicTM NX Cm-S100W program. Absorbance characteristics for Dongwha glaze were analyzed by using UV-Vis-NIR spectroscopy (UV-Vis-NIR spectroscopy, Jasco, V-770, Japan). Crystal phase analysis in the glaze was conducted by using X-Ray diffractometer (Dmax2500, Rigaku, Japan). Cross sectional microstructures of specimens were comparatively analyzed by using scanning electron microscope (JSM-6707M, Jeol, Japan), with EDS Mapping analysis being carried out. Cross sections of the glaze were observed by using transmission electron microscope (Tecnai F30, FEI, New Zealand).

\section{Results}

Specimens prepared by varying the copper oxide content and the heat treat were summarized in Fig. 1. Under the condition of $0 \mathrm{~L} / \mathrm{min}$ LPG, Dongwha glaze exhibited color formation in G-series, while it showed color formation in GY-series under the condition of $0.3 \mathrm{~L} / \mathrm{min} \mathrm{LPG}$. Under the conditions of 0.5 and $0.7 \mathrm{~L} / \mathrm{min} \mathrm{LPG}$, it showed color formation in R-series. Based on the color formation characteristics of the specimens, heat treatment can be presumed to have been realized in the oxidative atmosphere at 0 and $0.3 \mathrm{~L} /$ min LPG, while it can be presumed to have been realized in reductive atmosphere in the furnace at 0.5 and $0.7 \mathrm{~L} / \mathrm{min}$.

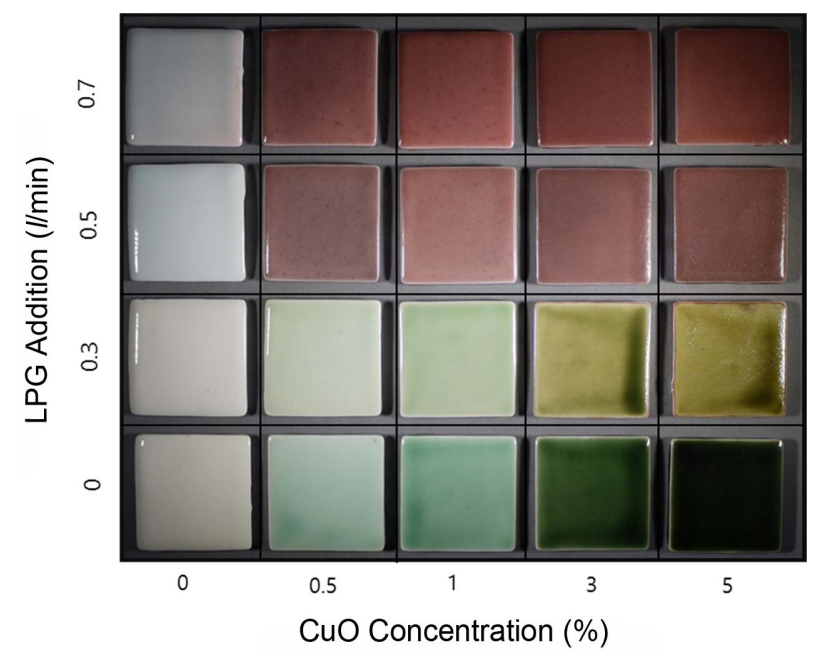

Fig. 1. Copper glaze samples prepared with varying $\mathrm{CuO}$ addition and under different sintering atmospheres.
Although smooth glaze surfaces and stable gloss were commonly observed up to $1 \mathrm{wt} . \%$ content, irrespective of heat treatment atmospheres, rough glaze surfaces due to bubbles could be affirmed with the copper oxide content as increased to 3 and $5 \mathrm{wt} . \%$. Also, degradation in the gloss was observed due to dull color formation of glaze and bubbles. Thus, the copper oxide (II) may be inferred to act as the cause for production of the bubbles.

To check whether the color formation of Dongwha glaze specimens is a phenomenon occurring in a part of the glaze layer, the specimens prepared in the atmosphere of $0.5 \mathrm{~L} /$ min. LPG were cut for observation of the cross sections of the glaze layer. As shown in Fig. 2, the color formation in glaze was affirmed to be the phenomenon occurring homogeneously throughout rather than in a limited part.

Distributions of CIELAB in Dongwha glaze specimens are shown in Fig. 3 as a function of the copper oxide (II) content per heat treatment atmosphere. Under the conditions of 0 and $0.3 \mathrm{~L} / \mathrm{min} \mathrm{LPG}$, it was affirmed that $\mathrm{CIEa}^{*}$ value became a '-' value and CIEb* value a '+' value as the copper oxide (II) content were increased so as to be distributed in Green series and Green-Yellow series, respectively. On the other hand, under the conditions of 0.5 and $0.7 \mathrm{~L} / \mathrm{min} \mathrm{LPG}$, CIEa* $b^{*}$ distribution became a '+' value in direct proportion as the copper oxide (II) content were increased, showing progression to Red series as the reducing atmosphere became intensified. Depending on the oxidation-reduction atmosphere, $a^{*}$ values for the specimens were affirmed to be increased in the opposite direction and $b$ values increased in the same $(+)$ direction as the copper oxide content were increased.

For the specimens with 3 wt.\% of copper oxide (II) heat
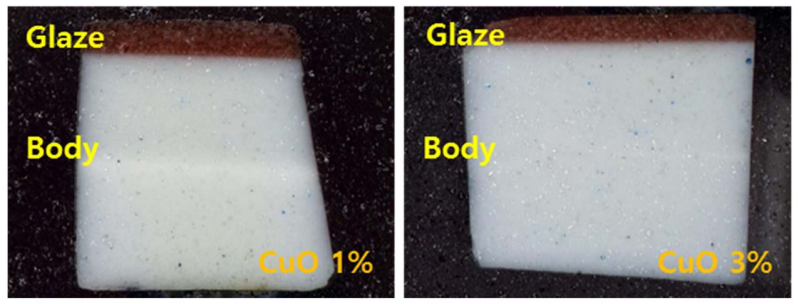

Fig. 2. Cross-section images of two samples showing homogeneous red glaze layers (samples sintered at LPG $0.5 \mathrm{l} / \mathrm{min}$ condition).
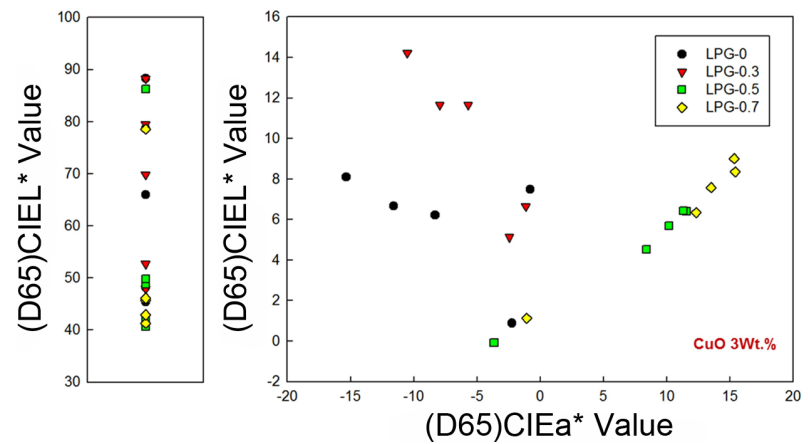

Fig. 3. CIELAB analysis on copper glaze samples. 
treated in different atmospheres, absorbance characteristics were analyzed by using UV-Vis-NIR spectroscopy (Fig. 4). The specimens heat treated at $0,0.3,0.5,0.7 \mathrm{~L} / \mathrm{min} \mathrm{LPG}$ showed different results. The specimens heat treated at 0 and $0.3 \mathrm{~L} / \mathrm{min}$ LPG showed a broad peak near the wavelength of $750 \mathrm{~nm}$, while those heat treated at 0.5 and $0.7 \mathrm{~L} / \mathrm{min}$ can be seen to show a high absorbance up to $560 \mathrm{~nm}$ followed by a rapid drop.

No narrow peak near $570 \mathrm{~nm}$ representing metallic nanocluster of $\mathrm{Cu}$ reported in the literatures were observed in all specimens. ${ }^{512)}$ Also, the broad peak near $430 \mathrm{~nm}$ associated with isolated $\mathrm{Cu}$ atoms did not appear. Existence of metallic copper atoms and nanoclusters which were reported as the major cause for color formation in Dongwha glaze could not be affirmed through UV-Vis-NIR spectroscopy analysis. In the case of oxidized specimens, all broad peaks were observed near $750 \mathrm{~nm}$ due to $\mathrm{Cu}^{2+}$. Intensities of the peak can be seen to be increased as the oxidative atmosphere became more intensified. Chromaticity of the specimens sintered in oxidative atmosphere can be seen to have green color due to the presence of $\mathrm{Cu}^{2+}$.

Crystal phases of the glaze layer were analyzed by using XRD. As shown in Fig. 5, broad peaks and quartz peaks were observed for $2 \theta=20-30^{\circ}$ showing amorphous phases at $0 \mathrm{~L} / \mathrm{min} \mathrm{LPG}$, while the peaks of quartz and metal $\mathrm{Cu}$ appeared at $0.3 \mathrm{~L} / \mathrm{min}$. Under the conditions of 0.5 and 0.7 $\mathrm{L} / \mathrm{min} \mathrm{LPG}$, all peaks corresponding to $\mathrm{Cu}, \mathrm{CuO}$ and $\mathrm{Cu}_{2} \mathrm{O}$ as well as quartz could be seen to appear. As the reductive atmosphere became intensified, the intensity of metal $\mathrm{Cu}$ peaks can be seen to become relatively stronger.

The observation results for microstructure of glaze layer using SEM are summarized in Fig. 6. In the case of specimens heat treated at 0 and $0.3 \mathrm{~L} / \mathrm{min}$ for the added amounts of LPG, no unique crystal formation, etc. were observed. In the specimens heat treated at 0.5 , and $0.7 \mathrm{~L} / \mathrm{min} \mathrm{LPG}, \mathrm{Cu}$ particles of 10 microns in size were observed around bubbles in the glaze layer. The distribution and the size of $\mathrm{Cu}$ particles showed no correlation with the heat treatment condi-

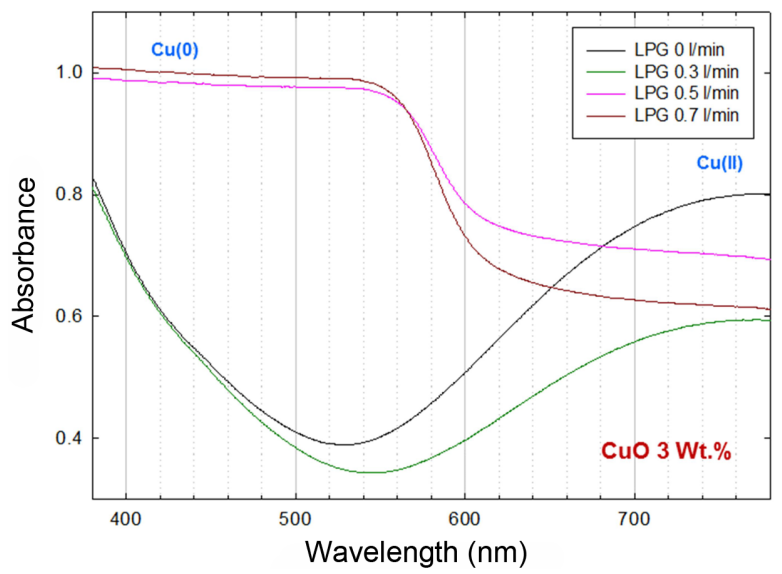

Fig. 4. UV-Vis-NIR spectroscopy analysis on the copper glaze samples with $3 \% \mathrm{CuO}$ addition sintered in different atmospheres. tions and the $\mathrm{CuO}$ content. Nano-sized $\mathrm{Cu}$ crystals discussed in many articles were not observed in any specimen in the observations using TEM (Fig. 7).

\section{Discussion}

$\mathrm{CuO}$ employed as the $\mathrm{Cu}$ source for Dongwha glaze is known to exist in diversified forms depending on the heat treatment temperatures and atmospheres. ${ }^{2,13,14)}$ While copper oxide (II) is dissolved to form $\mathrm{Cu}^{2+}$ in oxidative atmospheres, the specimens heat treated at 0 and $0.3 \mathrm{~L} / \mathrm{min} \mathrm{LPG}$ appear to exhibit green color. This is supported by the broad peak near the wavelength of $750 \mathrm{~nm}$ observed in UV-VisNIR spectroscopy analysis results. According to the XRD

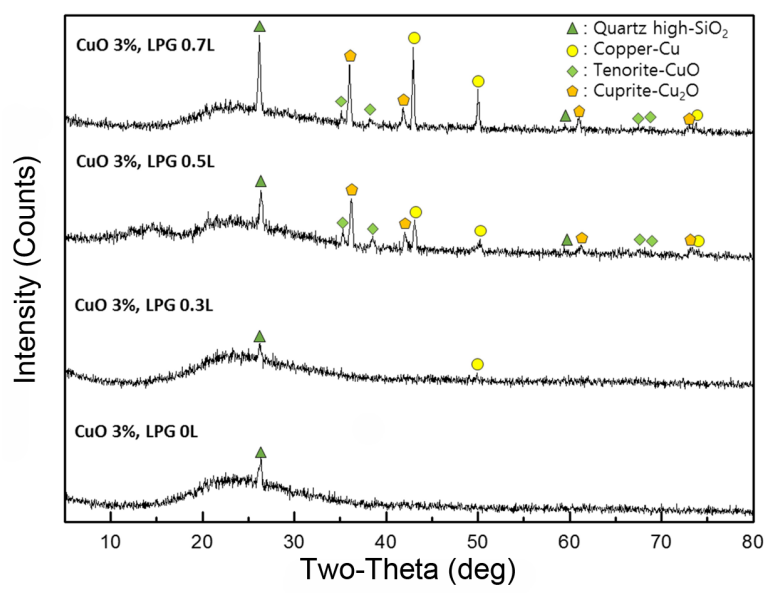

Fig. 5. XRD analysis on the copper glaze samples with $3 \%$ $\mathrm{CuO}$ addition sintered in different atmospheres.

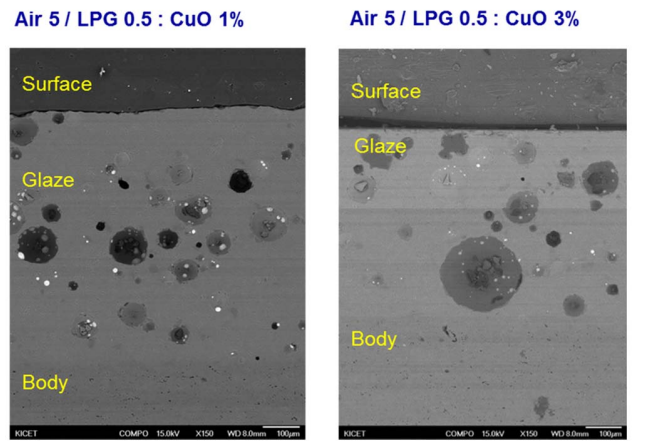

(a)
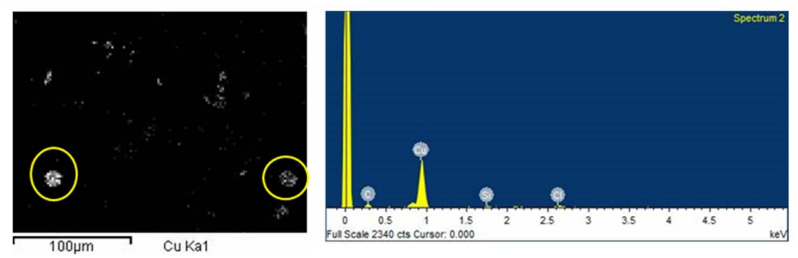

(b)

Fig. 6. (a) Microstructural analysis on the copper glaze samples sintered at LPG $0.5 \mathrm{l} / \mathrm{min}$ condition. (b) EDS analysis on the samples indicating $\mathrm{Cu}$ globules around pores in glaze layers. 
Air 5 / LPG 0.5 : CuO 1\%

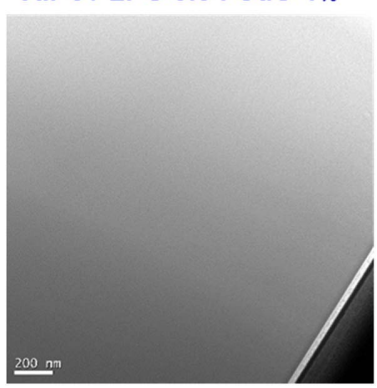

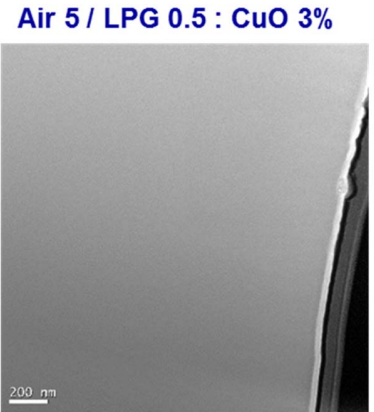

Fig. 7. Microstructural analysis on the copper glaze samples sintered at LPG $0.5 \mathrm{l} / \mathrm{min}$ condition using TEM. No crystals observed in both samples.

analysis results, formation of some metal $\mathrm{Cu}$ could be affirmed to occur in a weak oxidative atmosphere $(0.3 \mathrm{~L} / \mathrm{min}$ LPG). This suggests that $\mathrm{Cu}^{2+}$ dissolved in high temperatures has been reduced by combination with electrons produced in a glass structure or impurities. ${ }^{15)}$

$$
\mathrm{CuO} \rightarrow \mathrm{Cu}^{2+}+\mathrm{O}^{2-}
$$

Copper oxide (II) reacts with $\mathrm{CO}$ gas produced by combustion of LPG gas for reduction to $\mathrm{Cu}_{2} \mathrm{O}$ or $\mathrm{Cu}^{16-19)}$ According to the existing studies, $\mathrm{CuO}$ may be reduced in the order of $\mathrm{Cu}_{2} \mathrm{O}-\mathrm{Cu}$, or directly to $\mathrm{Cu}$, while the process of direct reduction to $\mathrm{Cu}$ is known to be preferred at relatively low temperatures. The rates of reduction to $\mathrm{Cu}$ are affected by $\mathrm{CO}$ gas concentration and temperature, and the reduction rates are expected to be increased in the present experiment when the flow rate of LPG gas are increased. Therefore, when the flow rate of LPG are increased, the reduction rates of $\mathrm{CuO}$ present in the glaze are increased so that the peak intensity of metal $\mathrm{Cu}$ also appears to be increased in the $\mathrm{XRD}$ analysis results.

$$
\mathrm{CuO}+\mathrm{CO} \rightarrow \mathrm{Cu}+\mathrm{CO}_{2}
$$

Plewa affirmed that reduction to $\mathrm{Cu}$ occurred within $1 \mathrm{~h}$ when a minor amount of $\mathrm{CuO}$ was exposed at $200^{\circ} \mathrm{C}$ to the mixed gas of $\mathrm{CO}-\mathrm{CO}_{2}$ similar to the combustion gas of LPG. ${ }^{17)}$ Considering such observation, most of copper oxide (II) added to the glaze up to the maximum 5\% appears to be reduced to metal $\mathrm{Cu}$ state under the assumption that sufficient $\mathrm{CO}$ gas was produced in the heat treatment process (of being held at $1250^{\circ} \mathrm{C}$ for $1 \mathrm{~h}$ after temperature rise at $3^{\circ} \mathrm{C} /$ min) applied in the present experiment. However, in the case of porcelain glaze, the liquid phase material formed by melting of the raw material as the temperature was raised comes to play a role of limiting the contact of $\mathrm{CuO}$ with $\mathrm{CO}$ gas. The glaze employed in the experiment was melted to form a liquid phase near $900^{\circ} \mathrm{C}$ where LPG gas began to be fed. The reduction process of $\mathrm{CuO}-\mathrm{Cu}$ begins as $\mathrm{CO}$ gas was adsorbed to the $\mathrm{Cu}$ sites of $\mathrm{CuO}$, and the liquid-phase glaze formed around $\mathrm{CuO}$ powder would limit the adsorption of
CO gas, because of which it is expected to act as a factor slowing down the reduction rates as well as the reduction intensity. Therefore, the reduction intensity of $\mathrm{CuO}$ is considered to be affected by both $\mathrm{CO}$ gas adsorption and formation rate of liquid phase.

Copper oxide (II) reacts with $\mathrm{CO}$ gas to form $\mathrm{Cu}$ nuclei in the reductive atmosphere, which are known to form $\mathrm{Cu}$ nanocluster capable of acting as the cause for red color after growth. ${ }^{3)}$ Further growth is known to cause the formation of metal $\mathrm{Cu}$ crystals having black color. Although all metal $\mathrm{Cu}$ peaks were affirmed according to the XRD analysis for the specimens produced at 0.5 and $0.7 \mathrm{~L} / \mathrm{min} \mathrm{LPG}$, no peaks showing $\mathrm{Cu}$ nanocluster were observed in the analysis results of UV-Vis-NIR spectroscopy. Also, no $\mathrm{Cu}$ nanoclusters were visible in the microstructure observations using SEM and TEM. On the other hand, multitudes of metal $\mathrm{Cu}$ globules were affirmed to exist around bubbles within the glaze layer according to the SEM analysis results.

No observation of $\mathrm{Cu}$ nanoclusters within the glaze layer is associated with the multitudes of $\mathrm{Cu}$ metal globules which have grown to a size larger than 10 microns. The metal $\mathrm{Cu}$ formed by reaction with $\mathrm{CO}$ gas is expected to form aggregation to lower the system energy and to grow causing precipitation around bubbles during the cooling process. When the aggregation and the precipitation occur, $\mathrm{Cu}$ concentration within the glaze layer is relatively lowered, extending the distance for $\mathrm{Cu}$ nuclei to move for formation of clusters. For such reason, it appears that no clusters of a few ten $\mathrm{nm}$ in size were observed whereas metal $\mathrm{Cu}$ crystals of micron sizes were observed in the microstructure analysis. Based on the analysis results of UV-Vis-NIR spectroscopy, metal $\mathrm{Cu}$ aggregation of smaller than $10 \mathrm{~nm}$ is considered to have been formed. ${ }^{20,21)}$

According to the XRD analysis results, crystal phases of $\mathrm{CuO}$ and $\mathrm{Cu}_{2} \mathrm{O}$ were observed in the specimens sintered in the reductive atmosphere. However, crystal shapes corresponding to the same were not observed in the microstructure analysis for the glaze layer. This seems to be originated from the oxidation reaction in cooling process. For the metal $\mathrm{Cu}$ particles formed near the glaze surface, the chemical state is known to be affected by atmospheres during the cooling process. ${ }^{2,22)}$ In the present experiment, feeding of LPG gas controlling the reductive atmosphere was stopped after being held at the maximum temperature for $1 \mathrm{~h}$, and the cooling process was conducted within the furnace which was not completely sealed. Thus, the metal $\mathrm{Cu}$ particles formed in the surface layer of specimen during this process appear to be capable of forming $\mathrm{Cu}_{2} \mathrm{O}$ and $\mathrm{CuO}$ by oxidation.

$$
\begin{aligned}
& 4 \mathrm{Cu}+\mathrm{O}_{2} \rightarrow 2 \mathrm{Cu}_{2} \mathrm{O} \\
& 2 \mathrm{Cu}+\mathrm{O}_{2} \rightarrow 2 \mathrm{CuO}
\end{aligned}
$$

Copper oxide (II) produces $\mathrm{O}_{2}$ or $\mathrm{CO}_{2}$ gas in both oxidative and reductive atmospheres. Because of this, the glaze surface appears to be roughened due to bubbles when the added amount of copper oxide is more than 3\%. Therefore, 
the use of less than $1 \%$ of copper oxide is considered desirable to prepare Dongwha glaze with smooth gloss.

\section{Conclusions}

Specimens of Dongwha glaze were prepared by variation in the copper oxide (II) content and the heat treatment atmospheres. Under the oxidative atmosphere conditions of 0 and $0.3 \mathrm{~L} / \mathrm{min} \mathrm{LPG}, \mathrm{CIEa}^{*}$ value became a '-' value and $\mathrm{CIEb}^{*}$ value a '+' value for color formation in Green series and Green-Yellow series as the added amounts of copper oxide (II) were increased. On the other hand, under the reductive atmosphere conditions of 0.5 and $0.7 \mathrm{~L} / \mathrm{min} \mathrm{LPG}$, $\mathrm{CIEa}^{*} \mathrm{~b}^{*}$ distribution became a '+' value in direct proportion for color formation in Red series.

The specimens sintered in the oxidative atmosphere could be seen to have green color due to $\mathrm{Cu}^{2+}$ formed by dissolution of $\mathrm{CuO}$. For the specimens sintered in the reductive atmosphere, $\mathrm{Cu}$ nuclei aggregation and existence of metal $\mathrm{Cu}$ globules of $\sim 10$ microns in size were affirmed in the glaze layer, while $\mathrm{Cu}_{2} \mathrm{O}$ and $\mathrm{CuO}$ were formed in the surface layer due to the oxidation during cooling process. Although the reduction specimens showing color formation in Red series of low chroma and dull tone appear to be affected by the combined effects of $\mathrm{Cu}$ nuclei aggregation, metal $\mathrm{Cu}$ globule and $\mathrm{Cu}_{2} \mathrm{O}$, no quantitative analysis of the same was conducted in the present study.

Since copper oxide (II) produces gas in both oxidative and reductive atmospheres, less than $1 \%$ of copper oxide should be used for Dongwha glaze to allow preparation of smooth and glossy Dongwha glaze.

\section{Acknowledgments}

The present article is the outcome of the study performed as the development project for strategic ceramic technology supported by Korea Institute of Ceramic Engineering \& Technology.

\section{REFERENCES}

1. J. Y. Kim, H. K. Cho, B. K. Jun, N. C. Cho, and C, H. Lee, "Material Analysis and Coloring Characteristics of Korean Traditional Copper-red Pigment (Jinsa) (in Korean)," J. Conserv. Sci., 27 [1] 31-40 (2011).

2. M. Wakamatsu, N. Takeuchi, H Nagai, and S. Ishida, "Chemical States of Copper and Tin in Copper Glazes Fired under Various Atmosphere," J. Am. Ceram. Soc., 72 [1] 169 (1989).

3. S. F. Brown and F. H. Norton, "Constitution of Copper-Red Glazes," J. Am. Ceram. Soc., 42 [11] 499-503 (1959).

4. J. Molera, C. Bayes, P. Roura, D. Crespo, and T. Pradell, "Key Parameters in the Production of Medieval Luster Colors and Shines," J. Am. Ceram. Soc., 90 [7] 2245-54 (2007).

5. P. Colomban and H. D. Schreiber, "Raman Signature Modification induced by Copper Nanoparticles in Silicate Glass,"
J. Raman Spectrosc., 36 884-90 (2005).

6. I. Nakai, C. Numako, H. Hosono, and K. Yamasaki, "Origin of the Red Color of Satsuma Copper-Ruby Glass as Determined by EXAFS and Optical Absorption Spectroscopy," J. Am. Ceram. Soc., 82 [3] 689-95 (1999).

7. A. Ram, S. N. Prasad, and K. P. Srivastava, "Viscosity of Copper Ruby Glass in and Below the Striking Range of Temperature," Glass Technol., 9 [1] 1-4 (1986).

8. H. S. Kim, T. K. Lee, K. G. Lee, K. H. Kim, and E. K. Lim, "Coloring Mechanism on Copper-Red Glaze (in Korean)," J. Korean Ceram. Soc., 23 [6] 15-24 (1986).

9. H. J. Eo and B. H. Lee, "Coloration Characteristics of Copper Red Glaze," Kor. J. Mater. Res., 23 [7] 399-403 (2013).

10. H. S. Hwang, A Scientific Study of Korean Copper-Red Ceramics (in Korean), pp. 146-55, in Ph.D. Thesis, ChungAng University, Seoul, 2008.

11. H. G. No, U. S. Kim, and W. S. Cho, "Study on the Glaze Properties via Unity Molecular Formula (I)," J. Korean Soc. Ceram. Arts, 11 [2] 81-94 (2014).

12. H. D. Schreiber, M. E. Stokes, and A. M. Swink, "Using Additives for Color Control in Copper Containing Glasses," pp. 315-322, in Ceramic Transactions, Vol. 141, Advances in Fusion and Processing of Glass III, Ed. By J. R. Varner, T. P. Seward, and H. A. Schaeffer, American Ceramic Society, Westerville, 2012.

13. S. Banerjee and A. Paul, "Thermodynamics of the System $\mathrm{Cu}-\mathrm{O}$ and Ruby Formation in Borate Glass," J. Am. Ceram. Soc., 57 [3] 689-95 (1999).

14. S. P. Singh, G. Prasad, and P. Nath, "Kinetic Study of $\mathrm{Cu}^{+}-$ $\mathrm{Cu}^{2+}$ Equilibrium in Sodium $\mathrm{Na}_{2} \mathrm{O}-\mathrm{Al}_{2} \mathrm{O}_{3}-\mathrm{B}_{2} \mathrm{O}_{3}$ Glass," $J$. Am. Ceram. Soc., 61 [9-10] 377-79 (1978).

15. J. Zhang and J. Sheng, "Formation and Optical Properties of Copper Nanoclusters in a Silicate Glass," Int. J. Hydrogen Energy, 34 3531-35 (2009)

16. F. Garcia-Labiano, L. F. de Diego, A. Abad, and P. Gayán, "Reduction and Oxidation Kinetics of a Copper-Based Oxygen Carrier Prepared by Impregnation for Chemical-Looping Combustion," Ind. Eng. Chem. Res., 43 8168-77 (2004).

17. J. Plewa and J. Skrzypek, "Kinetics of the Reduction of Copper Oxide with Carbon Monoxide," Chem. Eng. Sci., 44 [12] 2817-24 (1989).

18. E. A. Goldstein and R. E. Mitchell, "Chemical Kinetics of Copper Oxide Reduction with Carbon Monoxide," Proc. Combust. Inst., 33 2803-10 (2011).

19. A. A. Ahmed and G. M. Ashour, "Effect of Heat Treatment on the Crystallization of Cuprous Oxide in Glass," Glass Technol., 22 [1] 24-33 (1981).

20. P. A. Cuvelier, C. Andraud, D. Chaudanson, J. Lafait, and S. Nitsche, "Copper Red Glazes: A Coating with Two Families of Particles," Appl. Phys. A, 106 [4] 915-29 (2012).

21. A. Edgar, "Strong Red-Light Scattering from Colloidal Copper in ZBLAN Fluoride Glass," J. Non-Cryst. Solids, 220 78-84 (1997).

22. R. D. Schmidt-Whitley, M. Martinez-Clemente, and A. Revcolevschi, "Growth and Microstructural Control of Single Crystal Cuprous Oxide $\mathrm{Cu}_{2} \mathrm{O}$," J. Cryst. Growth, 23 113-20 (1974). 